\title{
Percepções acerca da condição de vida e vulnerabilidade à saúde de travestis
}

Perceptions on life conditions and health vulnerability of transvestites

Sylvia Maria Godoy Amorim¹, Fernanda de Sousa Vieira², Ana Paula Brancaleoni³

${ }^{1}$ Graduada em Psicóloga pela

Universidade Paulista (UNIP) - São Paulo

(SP), Brasil

sylmagorim@hotmail.com.

${ }^{2}$ Doutoranda em Psicologia pela Faculdade de Filosofia, Ciências e Letras da Universidade de São Paulo (USP) Ribeirão Preto (SP), Brasil.

fernanda.vieira1985@gmail.com.

${ }^{3}$ Doutora em Psicologia pela Faculdade de Filosofia Ciências e Letras da Universidade de São Paulo (USP) Ribeirão Preto (SP), Brasil.

anapaulabrancaleoni@gmail.com.
RESUMO: Objetiva-se discutir o processo de intervenção desenvolvido junto a travestis que enfrentam condições de extrema vulnerabilidade social. O trabalho foi desenvolvido em uma casa-pensão onde moravam e trabalhavam como profissionais do sexo, pautando-se nos pressupostos das Metodologias Participativas. Foram realizados 20 encontros, trabalhando-se os seguintes temas: condições de vida e moradia, relação com familiares e companheiros, relação com as drogas, acesso aos serviços públicos de saúde, autoimagem e relações com o corpo. Através da intervenção, favoreceu-se o fortalecimento dos laços grupais, bem como o desejo de cuidarem de si, refletindo acerca da condição de vulnerabilidade que vivenciavam e de formas para sua superação.

PALAVRAS-CHAVE: Vulnerabilidade; População trans; Metodologia participativa; Psicologia social comunitária.

ABSTRACT: It is discussed the process of intervention developed within transvestites who face extreme social vulnerability conditions. This work has developed in a house-pension where transvestites lived and worked as prostitutes, according to Participative Methodologies strategies. There 20 group sessions, where it discussed themes like conditions of life and housing, familiar relationships and partnerships, drug use, access to public health services, self-image and body-image. Trough this intervention, it was promoted group strength as well as the wish to self caring, reflexive process on the vulnerability conditions they lived and way to overcome this situation.

KEYWORDS: Vulnerability; Trans persons; Participative methodology; Community social psychology. 


\section{Introdução}

Peres (2002) afirma que a figura da travesti ${ }^{1}$ confronta o modelo heteronormativo na medida em que traz uma ruptura com a concepção binária de gênero, a qual estabelece a polarização entre o feminino e o masculino. Socialmente é atribuída à travesti a ambiguidade como sendo uma de suas características principais. Ela se configura como um terceiro ser no qual os signos referentes ao masculino e feminino se interpenetram. Assim, adota uma postura feminina, sem abdicar de seu "lado masculino" (GIRÃO; LIMA, 2009).

As travestis são tratadas pela sociedade brasileira como objetos de extrema discriminação, pautando-se na percepção de que o grupo excede e transgride os padróes normativos vinculados ao gênero e à sexualidade. São, portanto, consideradas monstros assustadores, inapropriadas para a aceitação social (LEITE JÚNIOR, 2012). Nesse sentido, a relação que estabelecem com seus corpos as marcam como aquelas que portam o que pode ser entendido como defeito visível, e, tendo por base as contribuiçóes de Goffman (1988), podemos dizer que carregam o estigma de uma categoria socialmente desacreditada. Como afirma o autor:

Acreditamos que alguém com um estigma não seja completamente humano. Com base nisso, fazemos vários tipos de discriminaçōes, através das quais efetivamente, e muitas vezes sem pensar, reduzimos suas chances de vida. Construímos uma teoria do estigma, uma ideologia para explicar sua inferioridade e dar conta do perigo que ela representa (GOFFMAN, 1988, p. 15).

O fato de portarem algo que se considera socialmente como 'defeito visível' é utilizado como forma de legitimação da violência que vivenciam. São percebidas

${ }^{1}$ Neste texto adota-se a referência feminina para travestis, de acordo com a maneira como as participantes do trabalho preferiam ser identificadas, bem como indica Pelúcio (2007). como indignas, imorais e, portanto, culpadas pela própria exclusão.

Segundo Guareschi (2001), nos processos de legitimação da exclusão é necessário que se encontre uma vítima expiatória sobre a qual recai e se descarrega a discriminação. Esta vítima é o próprio excluído, que é representado como um indivíduo que constrói a si próprio, independentemente das condições materiais de existência. Destarte, cria-se uma justificativa apartada das relaçóes excludentes em que o mesmo está engendrado. Tais justificativas atribuem a causa da exclusão a características e/ou comportamentos dos próprios sujeitos que a enfrentam.

A vivência constante da discriminação faz com que muitas travestis acabem por significar a condição de exclusão como inexorável, não se reconhecendo enquanto sujeitos de direitos, mas sim enquanto pessoas que até podem receber pequenos benefícios dados por órgãos governamentais ou não governamentais. Assim, acabam por acreditar que devem "se contentar" com a vida que possuem e a renda que conseguem por meio da prostituição, que se constitui, por vezes, como a única forma de sobrevivência que encontram, frente às dificuldades de acesso à profissionalização e à inserção no mercado, que também se pautam no padrão heteronormativo (PERES, 2002).

No sentido de favorecer a ruptura com esta condição, as intervençóes com essas pessoas devem primar pela valorizaçáo da cidadania e de seus direitos, colaborando para que se reconheçam como seres atuantes no mundo social (PERES, 2002).

Destaca-se que os processos de exclusão trazem intenso sofrimento para os sujeitos que os vivenciam, marcando intimamente suas existências e afetando diretamente suas condiçóes de saúde mental. Ressalta-se, ainda, que, ao se assumir a exclusão a partir do ponto de vista do sofrimento, em suas diferentes nuances, tem-se a condição de se recuperar o sujeito que acaba sendo perdido em análises estritamente econômicas e políticas. Contudo, ao mesmo tempo em que se contempla a dimensão da pessoa, isso não se dá em detrimento da visão do coletivo, ou mesmo desresponsabilizando o Estado de suas atribuiçóes no combate à desigualdade social (SAWAIA, 2001). 
Em vista das questốes apresentadas, propôs-se um processo de intervenção junto a um grupo de travestis que residem e trabalham na região central de uma cidade do interior de São Paulo. A escolha desse grupo foi pautada na condição de extrema vulnerabilidade enfrentada por essas pessoas, mas também no entendimento de que a mesma pode ser transformada.

Frente ao exposto, pretende-se analisar a intervenção desenvolvida, pautada nos pressupostos das Metodologias Participativas, junto a um grupo de travestis que vivencia condições de extrema vulnerabilidade social. Objetiva-se também apresentar e discutir as representaçóes do grupo acerca das principais questóes trabalhadas ao longo dos encontros, sendo elas: condiçóes de vida e moradia, relação com familiares e companheiros, relação com as drogas, acesso aos serviços públicos de saúde, autoimagem e relações com o corpo.

\section{Percurso metodológico}

Adotou-se como referencial teórico-metodológico as Metodologias Participativas, que, segundo Silva (2002), pressupóem o emprego de métodos e técnicas que possibilitem aos integrantes de um grupo a vivência dos sentimentos e percepçóes sobre determinados fatos ou informações, a reflexão sobre eles e a ressignificação de seus conhecimentos e valores, percebendo, assim, as possibilidades de mudanças.

Os grupos junto aos quais são construídas intervençóes a partir dos pressupostos das metodologias participativas deverão se constituir enquanto espaço em que se:

[...] privilegie o diálogo e o conhecimento mútuo de valores, experiências e afetos, que podem indicar um caminho mais sólido para as mudanças necessárias, que coloque o homem situado e contextualizado no centro do processo de transformaçâo incluindo ai aspectos afetivos, as informaçóes e fatos necessários à tomada de decisóes (SCHALL; STRUCHCHINER, 1995, p. 98).
Assim, os trabalhos desenvolvidos nessa perspectiva têm como foco e direção para os próprios sujeitos do processo. Outra potencialidade dos trabalhos realizados dentro desta orientação é a contribuição para a construção de novos significados através da interação, assim como o estabelecimento de redes de experiências (SILVA, 2002).

Entende-se que as intervençóes em grupo têm o potencial de favorecer a identificaçáo entre seus membros, o compartilhar de experiências e a troca de informações. A partir do conhecimento de realidades diversas e, ao mesmo tempo, semelhantes, se pode questionar a realidade enquanto algo dado e determinado, visando a que os sujeitos sociais se emancipem e promovam transformaçôes coletivas. Portanto, novos conhecimentos podem ser convertidos em novos propósitos e açóes quando os sujeitos estão inseridos em processos grupais.

A composição de um grupo para promoção de saúde e cidadania requer um processo que se inicia muito antes da primeira sessão e continua ainda depois de finalizada a última. Entende-se que a confidencialidade e o respeito diante de cada opiniáo sejam pontos de extrema importância, mantendo-se uma postura não invasiva diante das discussóes e da exposição da vida de cada componente, procurando-se sempre instigar aspectos que estão na base das questóes, sensibilizando por meio de reflexóes e construções coletivas do grupo.

Nesse sentido, a intervenção visou a promover espaços para questionamentos, desconstruçôes e composição de novos sentidos, de forma a favorecer a transformação de condiçốes de violência e exclusão, com vistas à emancipação desses sujeitos.

\section{Resultados e discussão}

\section{O TRABALHO COM O GRUPO}

A intervenção se deu em uma casa-pensão onde se reuniam, aproximadamente, 15 travestis que se prostituíam. Eles moravam no local e, algumas vezes, utilizavam-no para efetuar os programas. O trabalho de intervenção foi desenvolvido ao longo de 20 encontros, que tiveram frequência semanal, coordenados por duas 
psicólogas. O número de participantes nos encontros - que tiveram duração média de uma hora e meia - variou entre 10 e 12 pessoas.

A participação se deu de forma voluntária. Optou-se pela configuração de um grupo aberto, ou seja, que permitisse a entrada de participantes em qualquer momento do processo. Isto porque se pretendia a constituição de espaços facilitadores para ocorrência de reflexão e tomada de consciência de aspectos despercebidos, proporcionando uma atmosfera de aceitação, ânimo e socialização com reconhecimento dos pares enquanto possíveis companheiros em um processo de mudança, sem que houvesse a exclusão de pessoas que não estiveram presentes desde o início do processo. Para esta escolha, considerou-se também a significativa rotatividade de pessoas que moravam e frequentavam a pensão.

Aponta-se para a possibilidade de que a participação dos membros seja flutuante, o que, conforme Marchioni (1999), tem dois lados: por um lado, precisa ser estimulada, e, por outro, o participante necessita saber do desenvolvimento grupal para continuar participando dele, ter conhecimento de seus conteúdos. Assim, este grupo se constitui como uma célula onde ocorrem alguns desencontros, mas que permanece sempre em movimento. $\mathrm{O}$ mesmo autor afirma que é utopia pensar que todas as pessoas irão participar, no grupo. Ele enfatiza que o processo comunitário deve ser aberto e incluir as pessoas que vão chegando para não provocar exclusão. Isto significa que este é um processo flexível, para que haja a adaptação às condições reais de seus componentes e para que eles possam participar com suas particularidades. Desta forma, podem-se compreender os níveis diferenciados de participação, de engajamento.

No primeiro encontro com o grupo, conversou-se sobre os princípios que orientariam o trabalho. Ratificou-se o caráter coletivo da proposição e da realização de açóes, sendo que cada participante estaria livre para deixar o grupo a qualquer momento.

Os encontros ocorriam na sala da casa, que se encontrava habitualmente escura, com as janelas fechadas. Sempre era necessário abrir as cortinas e janelas para clarear o ambiente e aliviar o forte cheiro de crack. $\mathrm{Na}$ sala, estavam dispostas uma mesa e algumas cadeiras organizadas, arrumadas pelas participantes, para os encontros do grupo.

$\mathrm{Na}$ ocasião da primeira visita, o lugar causou, nas profissionais, um profundo mal-estar, pelas condiçóes precárias, até mesmo subumanas em que as travestis viviam. A maioria estava sob o efeito de drogas (em geral, crack) e apresentava sérios problemas de saúde, sendo uma grande parte portadora do vírus HIV. As condiçôes de higiene eram bastante ruins, sendo escassa a alimentação.

No início, ocorreram algumas dificuldades em adentrar o contexto de vida dessas pessoas, na medida em que se protegiam frente ao preconceito e aos processos de exclusão cotidianos, como afirmou uma delas:

Aqui a gente desconfia de tudo e de todos... Não dá pra confiar em ninguém... Nós estamos aqui conversando, mas... cada uma sabe seu lugar... faz alguma coisa... Aqui não tem amiga... (D).

A aproximação foi possível por meio de uma mediadora inserida no campo, que fazia o trabalho de promoção de saúde no local, através da distribuição de preservativos. Essa mediadora era membro de uma organização não governamental $(\mathrm{ONG})$ de profissionais do sexo da cidade e já havia estabelecido uma relação de confiança com as travestis. O vínculo com o grupo foi se estabelecendo aos poucos, sendo constituída, paulatinamente, uma relação de maior confiança e interesse pelo trabalho.

Houve a preocupação em não impor valores próprios e sim proporcionar ao grupo um lugar de liberdade para que as mesmas se expressassem da forma que se sentissem melhor.

O trabalho desenvolvido com as travestis visou essencialmente à configuração e ao resgate de uma condição de sujeitos de direito, da qual foram sendo usurpadas ao longo de suas vidas. Segundo Peres (2002), as relaçóes construídas por travestis vão se dando a partir das dificuldades que lhes são impostas pelos modelos dominantes de organizaçóes históricas culturais. Ao se defrontarem com elas, compõem estratégias de sobrevivência dentro de um mundo marginalizado, no qual as desigualdades sociais expressam seu poder. 
Desta forma, as travestis desenvolveram, em seus cotidianos, uma gama rica de estratégias de sobrevivência que merecem ser (re)conhecidas, para que, através desse movimento, também possam ganhar luz seus potenciais de resistência à discriminação e à inclusão perversa que vivenciam, favorecendo processos de emancipação.

Assim, entende-se a importância de se trabalhar pela autonomia deste grupo, construindo conjuntamente fissuras na atribuição socialmente estabelecida que as relegou ao lugar da impotência, na medida em que lidaram com a precariedade de oportunidades na relação com os grupos normalizados (CASTELLS, 1999).

Sendo assim, entende-se que o desenvolvimento do trabalho junto a este grupo apontou para além da condição de extrema violência e vulnerabilidade que seus membros viviam, revelando, também, a existência de potencialidades, até então, não reconhecidas pelas próprias travestis.

\section{CONDIÇÕES DE MORADIA}

Mereceu destaque a condição extremamente precária de moradia, sendo a mesma, no início do trabalho, inclusive, insalubre. Tratava-se de uma 'casa-pensão'. Era uma edificação bastante antiga, com problemas infraestruturais de toda ordem, tais como: infiltraçóes, fiação exposta, problemas hidráulicos e problemas sanitários, entre outros. O prédio, em suma, estava bastante distante de ser um local que julgaríamos adequados para moradia humana.

A pensão era controlada por uma cafetina, com a qual eram estabelecidas relações bastante contraditórias. Ao mesmo tempo em que vivenciavam condiçôes de violência e subjeção na relação com essa, a mesma também representa uma proteção contra a violência enfrentada externamente. Como referiam as travestis, a violência que enfrentavam na rua era ainda mais ameaçadora do que aquela que se reproduzia na relação com a cafetinagem.

Pagavam à cafetina uma quantia por mês, ou um valor por programa realizado, o que seria correspondente aos seus custos na casa. Contudo, a dinâmica do local era ditada pela mesma. Destaca-se que o controle das chaves do local estava com uma única pessoa, determinada pela própria cafetina, sendo que, por vezes, algumas travestis não conseguiam entrar ou sair $\mathrm{da}$ casa quando desejavam.

Muitas vezes, não conseguiam pagar a quantia estipulada para sua manutenção na pensão, tendo suspensa, por exemplo, a alimentação. A dificuldade de obtenção de alimentos também foi observada junto a este grupo de travestis. Elas se alimentavam de um 'sopáo', que era fornecido especialmente para pessoas em situação de rua, por um serviço de assistência social do município.

Ao longo do desenvolvimento do trabalho, notaram-se algumas mudanças na relação com o espaço e com a alimentação. Observaram-se maiores cuidados com a limpeza, com a abertura das janelas e cortinas e com a pintura da casa, bem como havia momentos em que uma das travestis cozinhava para as outras.

\section{FAMÍLIA E COMPANHEIROS}

No início dos contatos com o grupo, a maioria das travestis dizia que era plenamente aceita pelos familiares, mas que só os visitavam uma vez por ano. Contudo, identificava-se uma grande incongruência nestas falas. Analisando-se os relatos das mesmas, o que parecia ser relevante, na relação com os familiares, era o interesse, por parte desses, em seu ganho financeiro, isso quando havia uma boa remuneração na atividade de prostituição. Quando não possuíam uma boa remuneração, o distanciamento dos familiares era ainda maior. $\mathrm{O}$ fato é que a não aceitação familiar era algo muito difícil de ser vivido por elas. Dessa forma, muitas vezes, negavam para si mesmas a real postura assumida por suas famílias. Entende-se, portanto, a negação como uma defesa em relação à intensa angústia frente ao reconhecimento da não aceitaçáo por parte dos parentes.

A conversa mais franca acerca das relaçóes com as famílias, bem como de seus sentimentos sobre isso, foi se tornando possível na medida em que se fortalecia o vínculo entre o grupo e as psicólogas. A partir de então, puderam emergir a complexidade dessas relaçóes e as dificuldades enfrentadas por elas, sendo possível refletir acerca de suas vivências e sentimentos. A mudança no 
discurso sobre a família, por parte de uma das travestis, é bastante ilustrativa desse movimento:

Minha familia sempre me apoiou, sempre ( $P$ afirmou no inicio dos trabalhos com o grupo).

Ah, meu pai me cortou o dinheiro... disse que não ia me dar um centavo se eu não virasse homem... Acham que se eu fico sem dinheiro, eu volto para casa, mas eles não entendem... Se fosse isso... (P afirmou depois de um tempo de convivência com as psicólogas).

A questão de ter, ou não, companheiros fixos não era algo concordante entre o grupo. Apenas as travestis mais novas tinham relacionamentos dessa natureza, sendo as mesmas responsáveis pelo sustento financeiro do companheiro. As travestis mais velhas associavam a manutenção desse tipo de relacionamento à posição de 'mulher de malandro', ressaltando a questão da relação de exploração econômica, que, segundo elas, acabava por se configurar (GARCIA, 2009), como afirmou uma das travestis mais velhas:

Ela tem um namorado, um menino novinho de todo, um bofe, tadinha... Ela fala que ele ama ela, mas ela que paga as contas dele! Eu também amo assim... (D fala sobre o namorado de $P$ ).

As mais velhas questionavam, ainda, a 'masculinidade destes maridos', pois, como se consideravam biologicamente do sexo masculino, achavam que era impossível um homem heterossexual querer se relacionar com outro homem, conforme a fala de uma delas:

Elas falam: 'Ele é meu homem'. Você já viu homem gostar de travesti? Homem gosta de mulher. Quem gosta de travesti é bichinha... ( $G$ falando sobre relacionamentos amorosos).

Percebe-se que essas travestis que vivenciavam os processos de exclusão calcados nos padróes heteronormativos, assumiam-nos como único discurso possível.
Destaca-se que esses padróes opressivos são também reproduzidos através de suas percepçóes e juízos de valores acerca da orientação sexual e postura desses homens que mantêm relacionamentos estáveis com travestis.

\section{AUTOIMAGEM E RELAÇÃO COM O CORPO}

Ao se trabalhar com um grupo de travestis em condiçáo de extrema vulnerabilidade social, observou-se que o estigma e a exclusão são elementos constituintes do seu cotidiano, participando da construção de suas identidades.

Pode-se constatar que elas se defrontam constantemente com o sofrimento psíquico e com a dor ao se sentirem rejeitadas pela sociedade. Essa rejeição é associada tanto à homossexualidade quanto ao fato de imprimirem uma aparência feminina ao corpo, mesmo que tenham nascido biologicamente machos.

Muitas das travestis desse grupo também compreendiam a condição de exclusão social que vivenciavam como algo imutável. Não se reconheciam enquanto sujeitos de direitos, e aquilo que, por ventura, recebiam de órgãos governamentais ou ONGs era compreendido como benevolência ou favor. Suas formas de vida e trabalho eram representadas como as únicas possíveis, com as quais deveriam se contentar (PERES, 2002), conforme afirmou uma delas:

\section{A gente é brocada pela sociedade, náo tem o que fazer (D).}

Destacaram-se as dificuldades de acesso à profissionalização que se impóem às travestis, na medida em que elas se distanciam daquilo que a sociedade aceita e considera normal. Como contratar uma travesti? Segundo elas, a resposta frequente, por parte dos empregadores, era a de que "a sociedade era preconceituosa e comprometeria a imagem da empresa". Mesmo as travestis que tiveram acesso a alguma profissionalizaçáo, por muitas vezes obtida antes dos procedimentos de transformação de seus corpos do masculino para o feminino, não conseguiam ingresso no mercado profissional. A vivência de uma delas é bastante ilustrativa: no momento em que decidiu que não trabalharia como profissional do sexo, passou a enfrentar condiçóes ainda 
mais severas para sua subsistência, sendo que o único trabalho encontrado foi como lavadeira para pessoas envolvidas com o mercado do sexo, obtendo uma remuneração insuficiente.

Elas afirmavam que as ocupaçóes possíveis para travestis eram aquelas em que 'ficavam escondidas', que não seriam vistas por muitas pessoas que não fossem 'do seu meio' como, por exemplo, faxineiras de cafetinas. As outras habilidades só poderiam ser exercidas entre as próprias travestis, como troca de serviços: manicure, cabeleireira, costureira, estilista etc.

Foi observado, também, que, na busca por outras condiçôes de vida e sentidos sociais, algumas mudaram de cidade, estado ou até país. Ao se referirem às colegas que moraram por um período na Europa, intitulavamnas como 'europeias'. Estas travestis retornaram de tal estadia sem os recursos financeiros esperados, por se envolverem com pessoas que furtaram as reservas destinadas a sua manutenção econômica no Brasil. Assim sendo, voltaram às ruas para garantirem sua subsistência.

As compreensóes deterministas acerca das condiçóes que vivenciavam foram sendo problematizadas ao longo das intervenções com o grupo, refletindo-se acerca dos complexos processos de exclusão em que estão inseridas, mas também buscando caminhos coletivos para sua superação.

Frequentemente, referiam-se a si mesmas e a sua imagem de forma pejorativa, fato que também é encontrado na literatura (PELÚCIO; MISKOLCI, 2009). As autodenominaçôes compreendiam adjetivaçôes como: 'dragóes' (pessoas feias, que exibem uma aparência pouco feminina e desordenada, que náo corresponde a um padrão estético) e 'bichas' (já que entendiam como paradoxal o ato de serem homens que desejavam se passar por mulheres).

Olha, bicha! Que feia, toda descabelada... (P falando de $M$, que passou pelo grupo para dar boas vindas às psicólogas).

Travesti é assim mesmo: meio homem... Aqui, minha filha: você acha que tem alguma mulher aqui? Tudo homem, aqui é tudo homem! (D falando sobre a forma como as travestis da casa se relacionam entre si, concebendo que o masculino, identificado como homem, tem caracteristicas de agressividade).

Nossa, a que ponto eu cheguei... Olha isso: um dragão! Eu não sabia que eu tava tão feia assim... Olha o meu cabelo! A gente nem percebe a que ponto chega... não se enxerga... Como eu envelheci! Mas, eu concordo com o que eu disse: é muito duro viver como travesti... E se a sociedade não desbrocar a gente, a gente vai ficar brocada a vida inteira! ( $D$ ao assistir uma filmagem de si mesma).

O uso das 'tecnologias do corpo' disponíveis, como o silicone, era reapropriado por elas, a partir dos recursos que possuíam, sendo este corpo reconstruído a partir de um saber peculiar, que tinha como sua detentora legítima a 'bombadeira' (travesti que injeta silicone industrial de forma precária) (PELÚCIO, 2007).

Destacaram-se o sofrimento e os grandes esforços que empreendiam para garantir uma aparência mais feminina, com os poucos recursos financeiros de que dispunham, mesmo que isso se traduzisse em significativos riscos à saúde. $\mathrm{Na}$ medida em que não havia como pagar por intervençóes cirúrgicas e o tratamento hormonal não satisfazia às expectativas desse grupo, elas recorriam então às 'bombadeiras'. Entendiam que esta era a maneira possível de obterem o corpo que desejavam de forma mais rápida.

Em relatos de uma das travestis, a precariedade dos procedimentos que envolviam o uso do silicone industrial ficou ainda mais explicitada. Elas se referiram à falta dos cuidados, muitas vezes, por parte da própria pessoa que se submetia ao procedimento, não fazendo a ingestão anterior e posterior dos remédios (antibióticos), que, parcamente, preveniam infecçóes; ou negligenciando outras recomendaçóes para que o silicone ficasse 'seguro no lugar'. O alto risco da prática era ainda aumentado diante da falta das 'precauçóes' acima descritas, que eram inclusive indicadas pelas 'bombadeiras', sendo muito comum 'haver complicações'. Destaca-se também que a falta de procedimentos de assepsia em relação às seringas e agulhas, bem como em relação 
a outros materiais, aumentava a exposição às complicações para a saúde.

$A i$, mas a gente sabe que tá correndo risco... A bombadeira até fala pra tomar remédio depois, antes... mas a gente não toma, esquece... Teve uma lá que bombou num dia e no mesmo dia tava fazendo programa. Não pode, tem que ter repouso, colocar calcinha... pra ficar seguro no lugar $(F)$.

Mas eu até entendo... tem que trabalhar. Bicha que fica parada, não ganha! Se ela não vestir um salto e for pra rua, como que fica? ( $G$ falando dessa situação, complementando a fala de F).

Era frequente, por exemplo, o uso de pedaços de cabos de vassouras para a separação entre os seios. Esses cabos eram conseguidos no local onde era feito o procedimento, locais que, nem sequer, eram previamente lavados. Outro fato comum era o uso de cola instantânea ou esmaltes para fechar o orifício causado pela agulha.

Ao se analisar todas as questóes apresentadas, entende-se que não basta apenas a transmissão de informações, mas é importante uma preocupação acerca de como as mesmas serão trabalhadas junto à população em questão. A simples informação não incorpora a reflexão, a sensibilização, e, consequentemente, não acarreta mudanças pessoais significativas (SILVA, 2002). Assim, não bastam as informaçóes de que o uso de drogas ou de silicone industrial traz risco de morte, mas é essencial que haja espaços de reflexão, por parte das travestis, sobre essas questóes, sobre aqueles sentidos que já trazem, bem como sobre os seus próprios sentimentos. Contudo, também se destaca a importância do efetivo acesso aos recursos socialmente disponíveis, uma vez que o uso do silicone industrial, por exemplo, é fortemente condicionado à ausência de condiçóes financeiras para se optar por outra estratégia.

Destaca-se o papel da redução de danos. Esta estratégia surgiu no campo da dependência de substâncias psicoativas e corresponde à busca de uma minimização das consequências do consumo de drogas, sob o ponto de vista da saúde e dos aspectos sociais e econômicos nele contidos, sem necessariamente reduzir ou eliminar o seu consumo (BRASIL, 2003). Esta estratégia também ultrapassa a dependência química e é um princípio que pode ser aplicado a outras modalidades, como o uso de hormônios e silicone industrial pelas travestis. Entende-se assim a necessidade de açôes de reduções de danos nos processos de transformaçâo que as travestis imprimem ao próprio corpo.

\section{RELAÇÃO COM AS DROGAS}

Percebeu-se que a baixa autoestima, a desvalorização que a sociedade impóe às travestis e as consequentes condiçôes de vida facilitam o processo de iniciação ao uso do crack e outras drogas, que as levam à dependência química. Como aponta Souza,

Os usuários estão, notadamente, mais expostos a situaçóes de violência e, no caso de travestis e transexuais com dependência química ao crack, a condição se torna mais preocupante, principalmente pela vulnerabilidade social e as vivências transfóbicas às quais estão expostas (SOUZA, 2010, p. 1).

Faz-se importante salientar que, no início dos encontros com as travestis, muitas estavam debilitadas em decorrência do uso problemático das drogas, e com consequentes enfermidades provocadas pela baixa imunidade, culminando inclusive em mortes durante o período de realização do trabalho. Vale também ressaltar que elas eram portadoras do vírus HIV, com exceção de uma delas, e não realizavam o tratamento antirretroviral de forma adequada.

A maioria das travestis com as quais se teve contato e que eram usuárias especialmente de crack, referiuse ao uso como uma forma de 'passar o tempo', pois durante o dia não havia nada para fazer no local onde moravam e, por conta do preconceito, raramente saiam, a não ser para trabalhar à noite, nas ruas. Por medo da violência, nas poucas vezes que saiam durante o dia, procuravam estar em grupo, como afirmam: 
Ah, aqui não tem muito o que fazer... Então, a gente se droga pra passar o tempo (D).

Tá tudo drogada aqui... Hoje não tem ninguém são aqui... e assim vai (M).

Para outras travestis, a droga tinha o poder de acalmar, tinha a função de aliviar a dor mental, sendo pouco reconhecida a severidade dos malefícios à saúde por ela causados. Então, ainda que algumas travestis acreditassem que poderiam interromper seu uso quando quisessem, o consumo era algo que lhes trazia esse alívio, portanto, elas o mantinham.

Ah, eu paro quando eu quiser.. Bem, não faz, mas é tranquilo (M).

Tem hora que só se drogando que dá pra aguentar aqueles cliente na orelha! (P).

Ao longo do trabalho, a dependência química foi sendo reconhecida e algumas participantes expressaram o desejo de obter tratamento.

Assim, o uso da droga era percebido como um recurso frente à falta de perspectivas, diante do não reconhecimento de seus saberes e habilidades, culminando com o sentimento de serem "inaptas/incapazes" de realizarem outras atividades e assumirem posturas de ruptura com essa condição em que viviam, como afirmou uma delas:

Se a sociedade não fizer pel'a gente, não tem o que fazer, não tem futuro, não (D).

No coletivo, as aptidóes e os saberes individuais começaram a ser expressos, reconhecidos e compartilhados. Por exemplo, umas passaram a ajudar as outras nos cuidados com a beleza e com as roupas.

\section{ACESSO A SERVIÇOS PÚBLICOS}

Ao longo do trabalho com o grupo, algumas buscaram atendimento em instituiçóes públicas que possuíam programas para dependentes químicos. Contudo, não encontraram o acolhimento necessário, pois os mesmos não consideraram as diferenças, as singularidades, ou mesmo as dificuldades concretas de acesso enfrentadas pelas travestis.

Em relação a essas barreiras, podemos citar desde a dificuldade de transporte e a ausência de informação até a falta dos documentos civis básicos que são exigidos pelos serviços. Para além dessas questôes de ordem mais material, também se ressaltam as experiências de enfrentamento de preconceito e discriminação que se somavam em suas trajetórias de procura por atendimento, o que lhes conferia também uma postura resistente frente à busca de outros serviços públicos. Destacou-se, como exemplo, a busca por ajuda em Centro de Atendimento Psicossocial, destinado à atenção ao uso problemático de álcool e drogas, obtendo, como única ação desse serviço, o encaminhamento da atendida para testagem para o vírus HIV.

Ressaltou-se, além da dificuldade de acesso, a falta de preparo das equipes de saúde para o trabalho com essas pessoas, tendo essas equipes pautado suas açóes, muitas vezes, nos preconceitos que alicerçam as discriminaçôes.

A ação das travestis na relação com os aparatos de saúde explicitava também o preconceito e a desvalia por elas já interiorizadas. Isto ficava claro quando, por exemplo, elas procuravam o serviço de saúde (apenas o pronto socorro central da cidade) somente no período noturno, em que seriam menos vistas,o que as fazia acreditar que teriam maiores possibilidades de receberem atendimento.

Percebeu-se que uma das principais dificuldades enfrentadas ao longo do trabalho foi a interlocução com os serviços públicos de saúde e assistência, não havendo uma estrutura de rede bem constituída que favorecesse ações de caráter mais integral.

Sobressaltou-se, dessa forma, o descompromisso da política com o sofrimento dessas pessoas, na medida em que se trata de uma população que enfrenta dificuldades de toda ordem, mas que, contudo, não é reconhecida enquanto composta por sujeitos que merecem atençáo das políticas públicas, inclusive, não encontrando acesso ao mesmo atendimento recebido por aqueles que ocupam condições socialmente aceitas (SAWAIA, 2001). 
A questão do desrespeito à condição de sujeitos de direitos e ao exercício pleno da cidadania compareceu com bastante ênfase às conversas com o grupo, merecendo destaque os processos de estigmatização das travestis, bem como vivências de intenso preconceito e discriminação social, nas quais elas eram representadas como 'menos gente'.

Sendo assim, ocupando cotidianamente o lugar da rejeição, elas se defrontam com a discriminação, com a desigualdade social e de gênero, que produz outras referências marcadas pela marginalidade, pela impotência perante seus direitos e pela naturalização de sentimentos de conformismo e silêncio. As travestis são excluídas também dos sistemas educacionais e profissionalizantes, tendo como uma das únicas saídas a prostituição, para a provisão de seu sustento (BENEDETTI, 1997).

Entende-se, portanto, que a promoção da emancipação dos sujeitos - no caso, desse trabalho das travestis - é essencial na reconfiguração das pautas das políticas públicas. No que concerne ao uso problemático de drogas, destaca-se que o mesmo deve ser compreendido inserido no processo de construçáo social desses sujeitos, sendo que as políticas e ações que pretendam efetividade devem conhecer e considerar suas realidades.

\section{Considerações finais}

Diante do exposto, evidenciam-se ausências de todas as ordens em relação ao grupo em questão. Entende-se que a natureza do trabalho, dentro da perspectiva qualitativa, não permite fazer generalizações. Contudo, outros estudos encontrados na literatura indicam que a condição de vulnerabilidade apresentada no presente trabalho não é impar das travestis com as quais a intervenção foi desenvolvida.

A partir do contexto discutido, indica-se a urgência de se refletir acerca de ações de promoção de saúde e cidadania, mas também de redução de danos no que se refere ao uso problemático de drogas e transformaçóes do corpo junto a esta população.

Destaca-se, ainda, que a não problematização dos modelos socialmente instituídos como 'belo' e 'normal', ou seja, a aceitação e a naturalização dos padróes já estabelecidos colaboram também no processo de manutenção da baixa autoestima e da exclusão social de travestis. Sustentam-se, assim, estereotipias e preconceitos que alicerçam processos de discriminação.

Dessa forma, salienta-se a importância de um olhar mais atento e cuidadoso para essas pessoas, tanto por parte dos profissionais da saúde e assistência quanto das políticas públicas de uma forma mais ampla. Isso porque o processo de exclusão vivenciado e ratificado cotidianamente é, inclusive, reforçado pela ausência de políticas públicas adequadas, bem como pelo não acesso ao atendimento com qualidade nos serviços públicos existentes.

\section{Referências}

BENEDETTI, M. Toda Feita: Gênero e Identidade no Corpo Travesti. Corpus: série textos de divulgação, v. 008, n. 97, p. 19, 1997.

BRASIL, C. A perspectiva da redução de danos com usuários de drogas: um olhar sobre os modos éticos de existência. 2003. Dissertação (Mestrado em Psicologia Social) - Universidade Federal do Rio Grande do Sul, Porto Alegre.

CASTELLS, M. O poder da identidade. In: A era da informação, economia, sociedade e cultura. 2. ed. São Paulo: Paz e Terra, 1999.
GARCIA, M. R. V. Identity as a "patchwork": aspects of identity among low-income Brazilian travestis. Culture, health \& sexuality, v. 11, n. 6, 2009. p. 611-623.

GIRÃO, A. F.; LIMA, F. P. Nem azul, nem rosa: negociações e subjetividades na prostituição travesti. In: Reunión de Antropología del Mercosur, 8. Buenos Aires, 2009.

GOFFMAN, E. Estigma: notas sobre a manipulação da identidade deteriorada. Rio de Janeiro: LTC, 1988. 
GUARESCHI, P. Pressupostos Psicossociais da Exclusão: competitividade e culpabilização. In: SAWAIA, B. (org.). Artimanhas da Exclusão: análise psicossocial e ética da desigualdade social. 5.ed. Petrópolis,: Vozes, 2001.

LEITE JÚNIOR, J. Transitar para onde? Monstruosidade, (des)patologizaçao, (in)segurança social e identidades transgêneras. Estudos Feministas, v. 20, n. 2, p. 559-568, 2012.

MARCHIONI, M. Comunidad, participación y desarrollo: Teoria y metodologia de la intervención comunitaria. Madrid: Popular, 1999.

PELÚCIO, L. "Eu me cuido, mona": saúde, gênero e corporalidade entre travestis que se prostituem. Seminário Homofobia, Identidades e..., Florianópolis, 2007. p. 1-11,

PELÚCIO, L.; MISKOLCI, R. A prevenção do desvio: o dispositivo da AIDS e a repatologização das sexualidades dissidentes. Sexualidad, Salud y Sociedad..., n. 1, p. 125-157, 2009.

PERES, W. S. Biossociabilidade contemporânea e a expressão travesti. Revista de Psicologia da UNESP, v. 1, n. 1, p. 8-17, 2002.
SAWAIA, B. Artimanhas da Exclusão: análise psicossocial e ética da desigualdade social. 5 ed. Petrópolis,: Vozes, 2001.

SCHALL, V.T.; STRUCHCHINER. Educação no contexto da epidemia de HIV/AIDS: teorias e tendências pedagógicas. In: CZERESINA, D. ET. A. (Ed.). AIDS: Pesquisa Social e Educaçao. São Paulo: Hucitec, 1995.

SILVA, R. DE C. Metodologias Participativas para Trabalhos de Promoção de Saúde e Cidadania. São Paulo: Vetor, 2002.

SOUZA, E. K. Quando algumas travestis esbarram na dependência química: caminhos e espaços para o tratamento. In: FAZENDO GÊNERO, 9. Diásporas, Diversidades, Deslocamentos. Florianópolis, 2010. Anais... Florianópolis: Universidade Federal de Santa Catarina, 2010.

Recebido para publicação em dezembro de 2013

Versão definitiva em dezembro de 2013

Suporte financeiro: não houve

Conflito de interesse: inexistente 